\title{
CULTURA MAKER E ROBÓTICA SUSTENTÁVEL COMO ESTRATÉGIA PARA ENSINAR CONCEITOS DE ELETRICIDADE ${ }^{1}$
}

\section{Maker movement and sustainable robotics as a strategy to teach electricity concepts}

\section{João Batista da Silva}

ORCID http://orcid.org/0000-0003-3556-9881

Universidade Estadual do Ceará, Fortaleza, Ceará, Brasil

joaobathista82@hotmail.com

José Ademir Damasceno Júnior

ORCID http://orcid.org/0000-0003-4110-532X

Instituto Federal de Educação, Ciência e Tecnologia do Ceará, Fortaleza, Ceará, Brasil profademir7@gmail.com

\section{Darkson Fernandes da Costa}

ORCID http://orcid.org/0000-0002-8304-0723

Instituto Federal de Educação, Ciência e Tecnologia do Ceará, Fortaleza, Ceará, Brasil darkson@gmail.com

\section{Dayne Kelly Rodrigues Soares de Almeida}

ORCID https://orcid.org/0000-0001-6253-6255

Universidade Federal do Ceará, Fortaleza, Ceará, Brasil

dayneletras@yahoo.com.br

Recibido: 25 de setiembre de 2020

Aceptado: 22 de diciembre de 2020

\section{Resumo}

O Movimento Maker (MM) é uma metodologia fundamentada nos pressupostos do "faça você mesmo", com vistas a possibilitar que o aluno tenha interação real com o material concreto. Assim, neste artigo nós apresentamos uma experiência de robótica educacional utilizando lixo eletrônico como recurso didático para ensinar conceitos de eletricidade aos alunos do Ensino Fundamental. Os resultados mostraram que a proposta foi exitosa e possibilitou a aprendizagem de potência elétrica, corrente elétrica, resistência elétrica e interação matéria/energia. Baseados em nossa investigação, acreditamos que essa pesquisa seja relevante por possibilitar que as aulas de Ciências sejam mais interessantes para os alunos.

Palavras-chave: Cultura maker, Robótica sustentável, Conceitos de eletricidade, Ensino fundamental.

\begin{abstract}
The Maker movement (MM) is a methodology based on the "do it yourself" assumptions to enable the student to have real interaction with the concrete material. Thus, in this paper, we present an experience of educational robotics using electronic waste as a didactic resource to teach electricity concepts to middle school students. The results showed that the proposal was successful and enabled the learning of electrical power, electrical current, electrical resistance, and matter and energy interaction. Based on our investigation, we believe that this research is relevant because it allows science classes to be more interesting for students.
\end{abstract}

Keywords: Maker movement, Sustainable Robotics, Electricity concepts, Middle school.

1 Uma versão preliminar dessa pesquisa foi apresentada no V Congresso sobre Tecnologias na Educação. 


\section{Introduçáo}

A despeito do avanço tecnológico no Brasil nas últimas décadas, inúmeros recursos ainda não alcançaram a escola. Atualmente, ensinar Física nas escolas brasileiras ainda representa um grande desafio, principalmente na maior parte das escolas públicas regulares do país.

Dentre tantos desafios, destacam-se: a falta de laboratórios, carga horária insuficiente (em média são duas horas semanais), desvalorização do professor, entre outros. A pesquisa de Cerqueira e Sawyer (2007) revelou que a maioria dos estabelecimentos escolares do Brasil, que oferece Ensino Médio, é desprovido de infraestrutura e tem uma carga horária escolar reduzida, de quatro horas-aula por dia, para contemplar todas as disciplinas. E esta não é uma realidade apenas no Ensino Médio, mas de todos os outros níveis da Educação Básica, inclusive o Ensino Fundamental.

Os estudos de Sátyro e Soares (2007) mostraram a precariedade e as péssimas condições de ensino da maioria das escolas de Ensino Fundamental do Brasil, tanto no que diz respeito àinfraestrutura quanto aos recursos humanos, ou seja, a falta de professores com formação adequada para ensinar nas disciplinas específicas.

Nesse sentido, os autores asseveram que o problema da falta de infraestrutura escolar pode exercer influência significativa na qualidade do ensino. Por exemplo, prédios e instalações adequadas, acesso a livros didáticos, existência de biblioteca escolar, laboratórios de ciências, dentre outros, são variáveis que podem influenciar para que os alunos tenham um melhor desempenho escolar (Sátyro \& Soares, 2007).

Mais de uma década depois, Duarte, Gomes e Gotelib (2019) evidenciaram que esses problemas ainda persistem, sobretudo em escolas públicas municipais da área rural. Diante das situações supracitadas nos parágrafos precedentes, Moreira (2017) destacouque o ensino de Física na Educação Básicabrasileira está em crise. Dentre os principais motivos, o autor destaca que há más condições de trabalho, perda progressiva da identidade no currículo, conteúdos desatualizados, dentre tantos outros. Vale destacar que essa realidade não é específica do ensino de Física, reverbera em toda a área de Ciências (Química, Física e Biologia).

O ensino de Física, como, por exemplo, de eletricidade, enfrenta vários obstáculos, em especial no Ensino Fundamental, em que a disciplina está contida numa estrutura mais ampla, denominada de Ciências da Natureza. De acordo com Lima e Takahashi (2013), algumas dificuldades enfrentadas por parte dos alunos no Ensino Médio poderiam ser minimizadas se houvesse a introdução de conceitos específicos de eletricidade já nos primeiros anos do Ensino Fundamental.

Considerando este cenário, o que fazer para mudar essa situação? Diante dessas dificuldades, a literatura científica tem apontado algumas iniciativas de professores, dentro de suas possibilidades, que estão utilizando materiais de baixo custo para ensinar conceitos de Física na Educação Básica (Silva \& Sales, 2018; Rodrigues, Mota \& Souza, 2019). E para potencializar tais práticas, as pesquisas têm associado a utilização de materiais de baixo custo com metodologias de aprendizagem ativa e a Cultura Maker (Meira \& Ribeiro, 2016).

Nessa perspectiva, o objetivo desta pesquisa é investigar quais são as contribuições de uma oficina Maker de robótica básica, por meio de uma metodologia de aprendizagem ativa, utilizando lixo eletrônico para potencializar a assimilação de conceitos de eletricidade por alunos do $6^{\circ}$ ano do Ensino Fundamental nas aulas de Ciências. 
Este artigo está organizado da seguinte forma: na introdução, foram apresentados a problemática e o objetivo da pesquisa; na seção 2, será apresentado o referencial teórico da pesquisa; na seção 3, serão descritos os procedimentos metodológicos; na seção 4, serão discutidos os resultados da investigação; por fim, na seção 5 , serão apresentadas as considerações finais.

\section{Cultura maker e robótica sustentável}

O Movimento Maker (MM), que pressupõe a ideia do "faça você mesmo" ou "faça com outros", originou-se entre os anos de 1990 e a primeira década de 2000, mas foi após o lançamento da Revista Maker Movement, em 2005, e da Feira Maker, em 2006, que o MM se difundiu e se fortaleceu rapidamente pelo mundo. Em seguida, surge o Manifesto Maker, que postula uma série de premissas que caracteriza essa cultura (Gavassa et al., 2016, p. 02).

Dentre as premissas postuladas, destacam-se: a) ajudar uns aos outros para fazer algo e compartilhar uns com os outros o que criaram; b) não são apenas consumidores, mas são produtores e criativos, que sempre perguntam o que mais podem fazer com o que sabem; c) não são vencedores, nem perdedores, mas um todo fazendo as coisas de uma forma melhor.

Essas premissas destacam duas características básicas para todos que queiram realizar um trabalho utilizando o Movimento Maker (MM): a aprendizagem colaborativa e o protagonismo do indivíduo. Embora essa ferramenta possa ser usada em ambientes não-formais (Magalhães\& Morais, 2017), é no ambiente formal de educação que ela vem contribuindo de forma bastante positiva na formação de estudantes protagonistas, dentre estes, no ensino de Ciências (Meira\& Ribeiro, 2016).

De acordo com Medeiros et al. (2016), uma aula de Ciências utilizando o MM poderá promover e instigar ações diretas dos alunos na construção de soluções criativas para problemas multidisciplinares, através da manipulação de objetos reais. Segundo Santana et al. (2016), atividades do tipo Maker possibilitam situações para que os alunos possam ser protagonistas do seu próprio processo de aprendizagem. Esse tipo de processo, centrado no aluno, apresenta como pressuposto teórico o Modelo Composicional da Criatividade, desenvolvido por Teresa Amabile, entre os anos de 1980 e 1990.

Alencar e Fleith (2003) desenvolveram uma síntese para as ideias de Amabile. Nessa síntese, o modelo se apoia em uma tríade de componentes que dialogam e interagem entre si na formação dos processos criativos: I) as habilidades de domínio, II) os processos criativos relevantes e III) motivação intrínseca. Esse modelo apresenta um destaque para o caráter de interação social (Meira\& Ribeiro, 2016).

Essa necessidade de formação de um indivíduo, não só com competências e aptidões individuais, mas também com habilidade de se relacionar com os outros em sociedade e na resolução de conflitos, sempre foi contemplada nos documentos oficiais utilizados no Brasil como parâmetros para a construção de modelos educacionais. Assim, foi nos Parâmetros Curriculares Nacionais (PCNs) e, recentemente, na Base Nacional Comum Curricular (BNCC). Vale enfatizar que este trabalho teve como norte diretrizes comuns nesses documentos, que recomendam que as escolas proporcionem um ambiente, projetos e práticas pedagógicas favoráveis para que os estudantes desenvolvamum pensamento científico, crítico e criativo. Assim, proporcionando o exercício de sua autonomia e protagonismo,e dessa forma, estabelecendo uma relação direta com os pressupostos da cultura Maker. 
Os documentos supracitados apontam para a formação de um ser humano completo, que seja tanto detentor de habilidades e competências individuais quanto capaz de se relacionar em grupo, em sociedade. Sendo assim, o Movimento Maker se configura como um aliado na formação educacional dos estudantes brasileiros na atualidade.

Ademais, uma das tendências educacionais contemporâneas do século XXI para o ensino de Ciências é a implementação de metodologias de aprendizagem ativa, com a aprendizagem centrada no aluno. Diferentemente do método tradicional, no qual o professor ocupa a posição de protagonista, detentor e transmissor da informação. No método de aprendizagem ativa, o aluno passa a ser protagonista na construção de seu próprio conhecimento, todaviaum dos grandes desafios para a implementação das metodologias ativas é utilizar recursos didáticos pertinentes/condizentes com a proposta, a fim de melhorar/elevar o nível de desempenho acadêmico dos alunos.

Considerando-se que as metodologias ativas preconizam desenvolver no aluno uma aprendizagem significativa, consoante Damasceno Júnior (2020), os professores devem priorizar esta forma de aprendizagem para os estudantes, pois simboliza uma relevante alternativa para romper com metodologias tradicionais. Para tanto, deve-se lançar mão de metodologias construtivistas, tendo o propósito de que o conhecimento sofra uma transformação, sendo preciso transcender/superar a condição deaprendizagem mecânica, de forma que os conceitos trabalhados passem a fazer sentido para os estudantes.

Algumas pesquisas evidenciaram que os alunos que tiveram aulas com metodologias ativas obtiveram desempenho acadêmico superior aos alunos que tiveram somente aulas tradicionais (Silva, Sales\& Castro, 2019). Outrossim, a maioria dessas pesquisas utilizou alguns recursos didáticos diferenciados para potencializar essas práticas, dentre eles recursos tecnológicos como plataformas digitais, entre outros.

E quais seriam as contribuições da Robótica Educativa, já que essa área recentemente vem, aos poucos, sendo explorada em atividades escolares? A Robótica é uma área tecnológica relativamente recente, caracterizada por se relacionar fortemente com as áreas de mecânica, eletrônica e computação. No geral, essa área trata de sistemas compostos por máquinas automáticas e controladas por circuitos integrados programáveis (Santos, Nascimento\& Bezerra, 2010).

Isto posto, na próxima serão apresentados os procedimentos metodológicos da pesquisa.

\section{Materiais e Métodos}

Quanto à abordagem, esta pesquisa tem caráter qualitativo. Uma pesquisa qualitativa, segundo Borba (2004,p.2), "é aquela que prioriza procedimentos descritivos à medida em que sua visão de conhecimento explicitamente admite a interferência subjetiva, o conhecimento como compreensão que é sempre contingente, negociada e não é verdade rígida”.

Quanto aos procedimentos técnicos, foi realizado um estudo de caso com 30 alunos do $6^{\circ}$ ano do Ensino Fundamental de uma escola pública municipal de Fortaleza. Um estudo de caso é um tipo de investigação empírica envolvendo um fenômeno, um indivíduo ou um grupo em seu contexto real, a partir de uma exploração intensa de um único caso (Yin, 2001).

Por motivos éticos, o nome da escola e dos alunos foram preservados. Inicialmente, foi elaborado o planejamento para alinhar a aprendizagem, considerando as dire- 
trizes da expectativa de aprendizagem da Secretaria Municipal de Educação (SME), com o Documento Curricular Referencial do Ceará (DCRC), também com a Base Nacional Comum Curricular (BNCC).

Após o planejamento, as atividades foram realizadas em três etapas.

\subsection{Etapa 1}

Foi esclarecido para os alunos sobre o problema do acúmulo e descarte inadequado do lixo, e como o aumento das Tecnologias Digitais contribuíram para aumentar a produção de lixo eletrônico, o qual contém em sua composição alguns metais tóxicos prejudiciais ao organismo humano e ao ambiente. Lixo eletrônico são todos os resíduos resultantes de eletrodomésticos e/ou equipamentos eletroeletrônicos, como, por exemplo, televisores, celulares, computadores, entre outros. Além disso, foi explicado que um dos grandes desafios para a sociedade contemporânea consiste na coleta, organização e descarte consciente do lixo eletrônico,com o intuito de evitar a contaminação do meio ambiente.

Diante dessa problemática, explicitou-se para os alunos a proposta de reaproveitar o lixo eletrônico de forma educativa. Em virtude disso, foi pedido para que os alunos trouxessem para a escola alguns tipos de eletrônicos, caso tivessem em casa e sem mais utilidade. Na semana seguinte, os alunos trouxeram para a escola alguns equipamentos com defeito e que não tinham mais utilidade, como: aparelho de DVD, controle remoto, mouse óptico, entre tantos outros.

\subsection{Etapa 2}

Inicialmente, em buscada apreensão dos conceitos de eletricidade pelos estudantes, realizou-se um momento para a identificação de seus conhecimentos prévios. A referida ação, também, teve o propósito de buscar estratégias mais adequadas para facilitar a conexão dos novos conceitos, que deverão ser adquiridos através das atividades experimentais,com os conhecimentos pré-existentes na estrutura cognitiva de cada indivíduo.

Por conseguinte, foi explicado sobre conceitos básicos de eletricidade (corrente, resistência, potência e diferença de potencial) e circuitos elétricos; o que seria necessário para dar continuidade ao projeto. De acordo com Rodrigues, Mota e Souza (2019), para o ensino de eletricidade em atividades experimentais, é necessário o domínio de alguns conceitos básicos, por meio de uma leitura introdutória, de maneira que possa fornecer ao aluno subsídios para estabelecer significados.

Para tanto, foram disponibilizados aos alunostextos contextualizados sobre eletricidade associados às atividades experimentais que seriam realizadas com eles, de acordo com o previsto neste projeto. Ademais, esses estudantes, de forma colaborativa e crítica, discutiam sobre os conceitos físicos abordados, colocando em prática uma dinâmica de elaboração e reelaboração desses conceitos por meio da mediação do professor.

Nesse sentido, as aulas sobre os conceitos de eletricidade foram planejadas para proporcionar aos alunos uma compreensão crítica dos conhecimentos científicos e tecnológicos da área de eletricidade. É o que Silva e Batinga (2019) denominam de 
alfabetização científica, a qual "possibilitará que o indivíduo tenha não somente a capacidade de compreender e interpretar o mundo natural, social e tecnológico, mas também para saber agir sobre ele, modificá-lo (Damasceno Júnior \& Romeu, 2019, p. 5), o que é uma condição essencial para a proposta de uma atividade Maker.

Dessa forma, essa etapa foi necessária para instigar os alunos para identificar problemas, pesquisar e propor alternativas de reaproveitamento do lixo em aulas de robótica educativa.

\subsection{Etapa 3}

Nesta fase, foi solicitado que os alunos formassem grupos. Primeiramente, os alunos, orientados pelo professor, montaram um carrinho utilizando material reaproveitável (Figura 1).

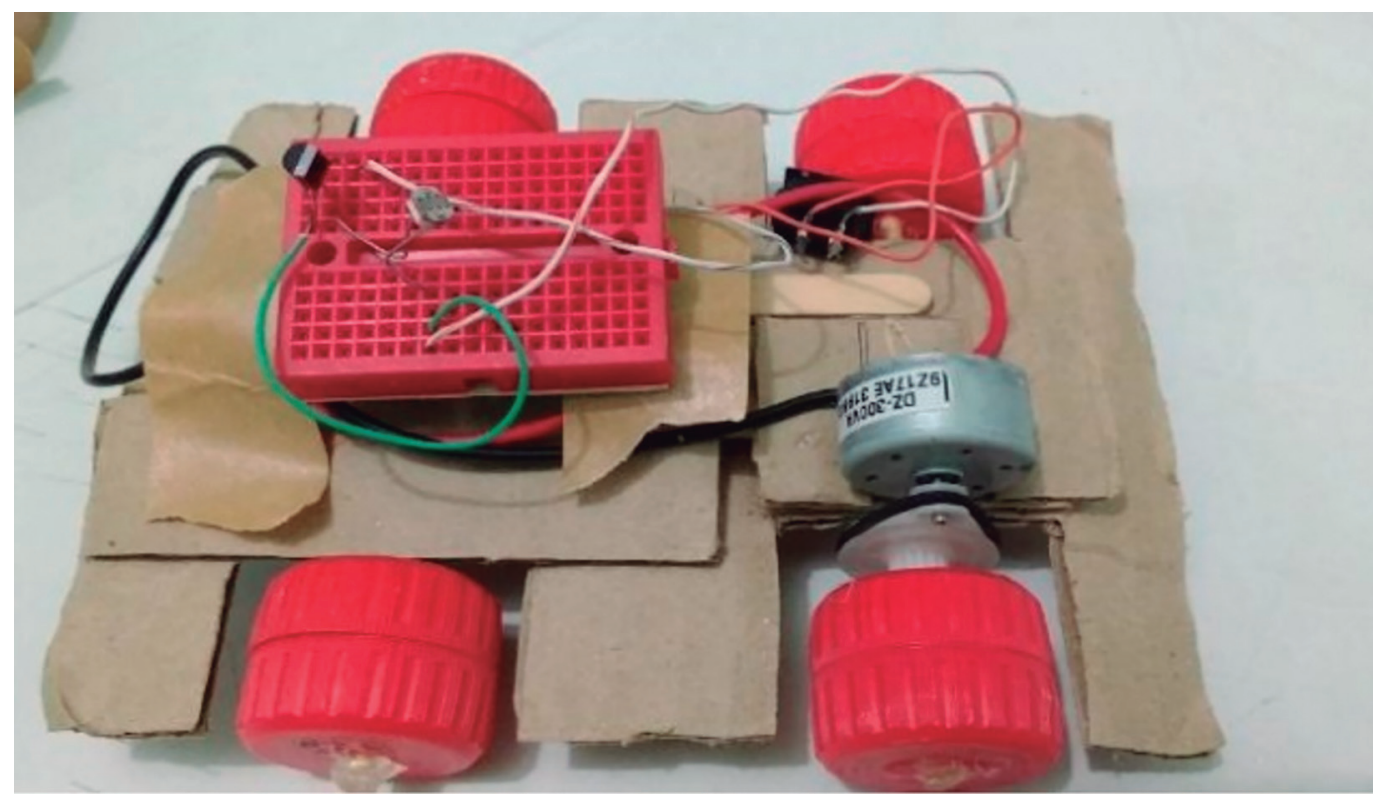

Figura 1: Carro construído pelos alunos utilizando material reciclável.

Prioritariamente, na construção foram utilizados materiais recicláveis: para o chassi foi utilizado papelão; as rodas foram feitas com tampas de garrafa PET encontradas em casa; os eixos das rodas foram feitos com palitos; e a correia foi feita com liga.

Os alunos exercitaram a curiosidade intelectual e a imaginação, componentes de um pensamento científico, tendo em consideração selecionar os materiais recicláveis mais apropriados para a montagem e designer do carro experimental. É importante destacar que, apesar das atividades experimentais propostas terem sido planejadas ainda na elaboração deste projeto, cada estudante exerceu sua autonomia e protagonismo para construir os protótipos de forma criativa. Desta feita, atendendo às premissas da cultura Maker.

Com relação à parte propulsão, se trata de um motor elétrico, o qual foi retirado de aparelho de DVD. A proposta foi utilizar a oficina, com materiais recicláveis, para construção de carros comandados/acionados por um circuito elétrico utilizando sensores luz (Figura 2). Vale salientar que, em momentos como esse, os conceitos sobre eletricidade anteriormente abordados nas leituras dos textos contextualizados, e dis- 
cutidos de forma colaborativa, eram constantemente revisitados, vislumbrando uma aprendizagem significativa.

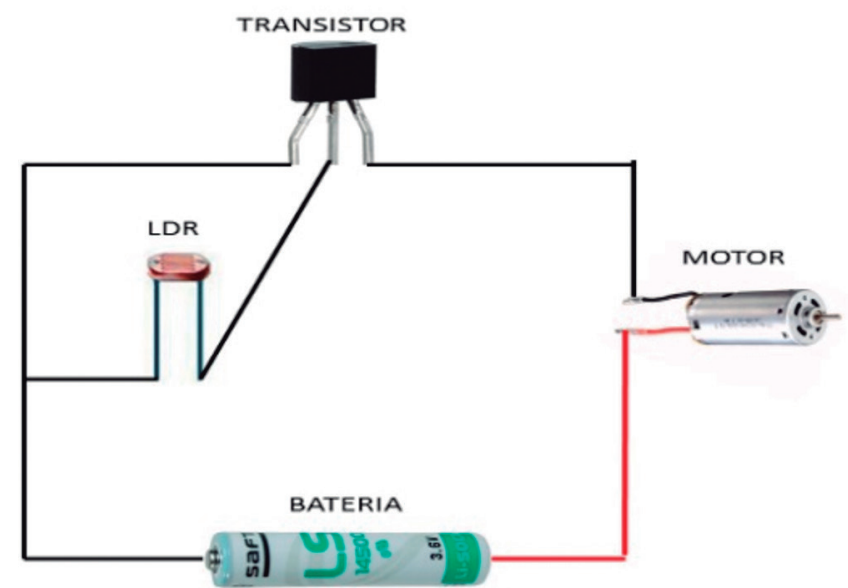

Figura 2: descrição da estrutura do circuito elétrico do carro.

No circuito foi utilizado um LDR (Light Dependent Resistor), umfotoresistor variável, ou seja, quanto mais luz incidir sobre ele, menor será sua resistência à corrente elétrica. Sendo assim, quanto maior for a incidência de luz, maior será a corrente elétrica que chegará ao motor (Figura 1), e consequentemente, mais rápido o carrinho se deslocará. Destarte, na próxima seção serão discutidos e apresentados os resultados.

\section{Resultados e discussóes}

Durante a apresentação do projeto e a prática das oficinas, foi percebido que os alunos têm pouca, ou quase nunca, atividades práticas. Acredita-se que, em parte, este fato esteja associado à falta de estrutura física da escola, que não tem laboratório de Ciências. Contudo, após as atividades das oficinas foi observado que uma das possibilidades de atenuar esta situação é utilizar materiais de baixo custo, jápreconizado por alguns autores (Silva\& Sales, 2018; Rodrigues, Mota\& Souza, 2019).

Por meio de observações e demonstrações do funcionamento do carro experimental pelos alunos, seguidas de suas explicações, acredita-se que eles puderam assimilar conceitos de eletricidade (corrente, resistência e potência), assim como aprenderam conceitos de mecânica (torque e velocidade) e interação matéria/energia, além de compreenderem ser possível reaproveitar o lixo eletrônico de forma educativa, utilizando esse material associado à metodologia proposta pela Cultuta Maker, do faça você mesmo.

Ainda, é importante dar ênfase ao fato de que os estudantes compreenderam, que quanto maior a incidência de luz no LDR maior seria a intensidade da corrente elétrica que atravessará o motor. E consequentemente, maior a velocidade empregada pelo protótipo. Tal afirmação se apoia através das demonstrações e argumentações apresentadas para o funcionamento do carrinho pelos alunos, apesar deles cursarem, ainda, o $6^{\circ}$ ano do Ensino Fundamental. Defende-se que esse processo foi bem intuitivo para eles, facilitando, desse modo, a compreensão dos conceitos envolvidos. 
Assim, posteriormente foitrabalhado a relação de proporcionalidade inversa estabelecida entre as grandezas físicas, "resistência elétrica" e "intensidade da corrente elétrica”, verificadas por meio da seguinte expressão matemática:

$$
R=\frac{U}{i} \text { Equação } 1
$$

\section{Equação 1}

onde,

R: Resistência elétrica (Ohm)

U: Diferença de potencial (Volt)

i: Intensidade da corrente elétrica (Ampère)

Isto posto, é relevante pontuar que, através da utilização de materiais descartáveis e recicláveis, como, por exemplo, um motor retirado da sucata de um DVD, dentre outros dispositivos elétricos, os estudantes puderam constatar um processo de geração e utilização da energia elétrica. Ademais, eles, também, tiveram a oportunidade de dimensionara importância da energia elétrica para a humanidade, tanto para um melhor armazenamento de alimentos quanto para um deslocamento rápido e seguro, entre outras tantas possibilidades, tudo com base nas discussões empreendidas e associações feitas com outros aparelhos usadosno cotidiano dos indivíduos.

De acordo com Santana et al. (2016), as atividades makers em ambientes de aprendizagem construcionistas, além de estimular a criatividade, possibilitam tornar os alunos protagonistas no desenvolvimento de sua própria aprendizagem. $\mathrm{Na}$ figura 2, são apresentadas as atividades práticas das oficinas.

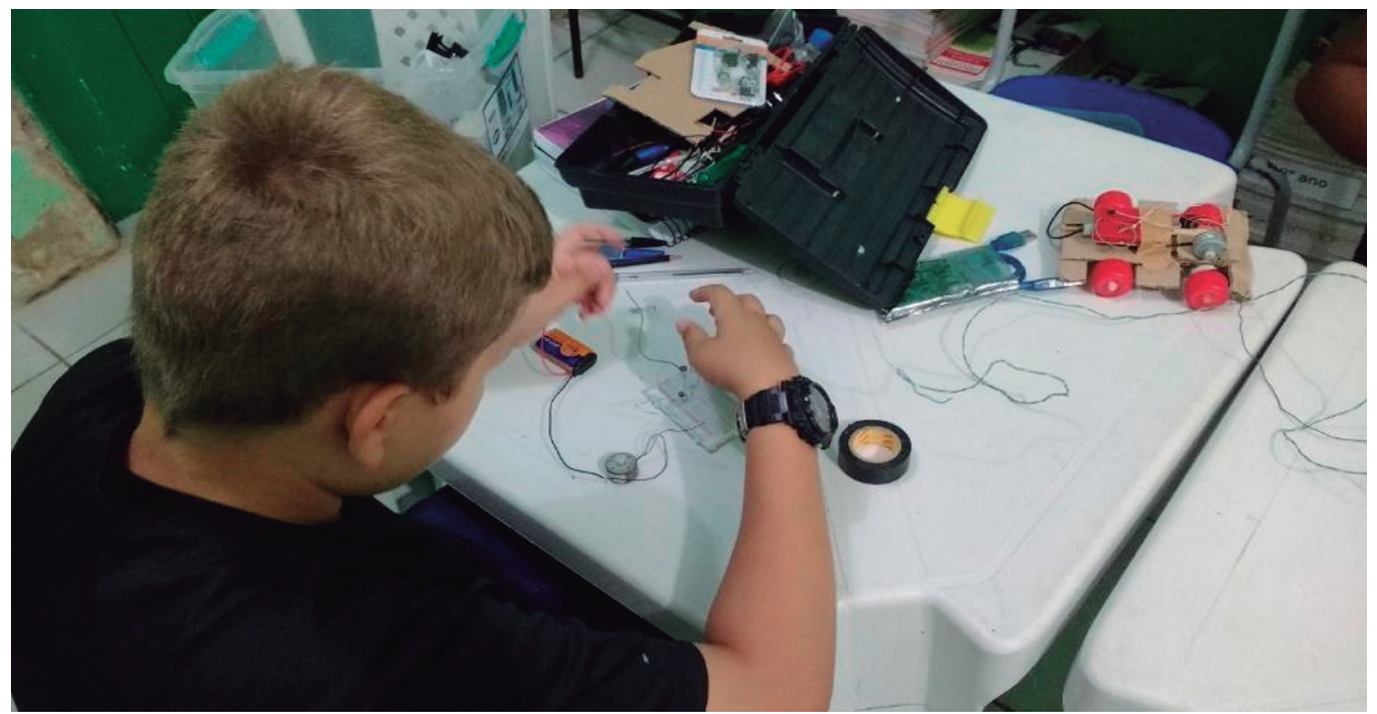

Figura3: Aluno construindo o carro nas oficinas.

Durante a parte prática, notou-se que os alunos ficaram curiosos para entender como funcionava os componentes eletrônicos. A curiosidade foi essencial para dar continuidade ao projeto, pois acredita-se que a ausência desse elemento dificultaria o andamento das oficinas. Os resultados obtidos vão ao encontro de Silva e Sales (2018), ao afirmarem que o interesse e a curiosidade dos alunos são variáveis que devem ser consideradas no processo de ensino da disciplina. E que essa curiosidade é potencializada quando os alunos percebem que eles mesmos podem construir seus experimentos de baixo custo com 
materiais fáceis de serem encontrados no seu cotidiano. Além disso, esses resultados também coadunam com os pressupostos de Meira e Ribeiro (2016), ao afirmarem que a inserção de estudantes em contexto de formação científica potencializa o desenvolvimento e a aplicação dos conceitos estudados na sala de aula para a produção tecnológica.

De acordo com Dornelles et al. (2019), o ensino da Robótica Educacional é, principalmente na Educação Básica, desafiador, e este fato tem apontado para o uso de metodologias deensino que sejam lúdicas e ao mesmo tempo didáticas. Essa associação tem se mostrado eficaz para o desenvolvimento das competências necessárias à robótica educacional. Dessa forma, as atividades Maker poderiam auxiliar os alunos a terem atitudes cada vez mais conscientes diante do saber tecnológico e científico, e suas implicações para o meio ambiente (Lopes et al., 2019).

Conforme destacam Silva e Sales (2018), acredita-se que atividades de baixo custo, aos poucos, apresentam-se como uma alternativa relevante para possibilitar o ensino de Ciências, todavia, vale ressaltar que não é uma proposta para substituir o laboratório de Ciências, mas para tentar contornar a situação causada pela sua falta. Confirma-se, no grupo de trabalho escolar analisado, que a atividade desenvolvida gerou interesse. Nesse sentido, acredita-se na relevância deste trabalho por possibilitar a aprendizagem de conceitos científicos em atividades práticas utilizando lixo eletrônico nas aulas de Ciências.

Ademais, acredita-se que esta pesquisa poderá incentivar investigações futuras, como, por exemplo, analisar o desempenho cognitivo dos alunos nas avaliações internas e externas, após inserção da mesma estratégia de ensino utilizada neste trabalho.

Todavia, defende-se que a estratégia de ensino adotada neste trabalho não representa a prescrição de um método indefectível para o ensino de Ciências, porém, configura-se como uma alternativa bastante viável. Concomitantemente, é imperativo que os professores se apropriem dos fundamentos da cultura Maker, seja em sua formação inicial ou continuada, com o intuito de que interpretações errôneas sejam descartadas, para assim obter maior proveito de seus benefícios no processo de aprendizagem.

\section{Consideraçóes finais}

O objetivo deste trabalho foi pesquisar quais as contribuições que uma oficina Maker de robótica básica, por meio de uma metodologia de aprendizagem ativa, utilizando lixo eletrônico, poderia proporcionarà aprendizagem de conceitos de eletricidade, numa turma do $6^{\circ}$ ano do Ensino Fundamental. Para tanto, foram realizadas oficinas de robótica, utilizando lixo eletrônico, baseada nos pressupostos do Movimento Maker. Os resultados mostraram que, a despeito de todas as dificuldades encontradas por professores, é possível ensinar Ciências de maneira criativa. Verificou-se que os alunos assimilaram conceitos de eletricidade, mecânica, interação matéria/energia, dentre outros, a partir do que preconiza a cultura Maker, ou seja, compreender fazendo. Além disso, levar o estudante a refletir sobre as possibilidades de reaproveitar o lixo eletrônico de forma educativa instiga nele a criatividade e o protagonismo para que, baseado em conhecimento científico, ele possa futuramente propor soluções para os problemas da sociedade contemporânea, dentre eles o problema da poluição ambiental. Nesse viés, defende-se que esta pesquisa poderá incentivar investigações futuras, como, por exemplo, analisar o desempenho cognitivo dos estudantes, após 
contato com a mesma estratégia de ensino utilizada neste trabalho. Outrossim, destaca-se que essa não é uma proposta para substituir os poucos laboratórios de Ciências que têm na minoria das escolas, muito menos a prescrição de um método infalível de ensinar Ciências, mas uma alternativa para tentar atenuar os problemas de sua ausência. Entretanto, recomenda-se para os professores uma fundamentação teórica e metodológica sobre a cultura Maker,com a finalidade de que sejam melhor exploradas suas potencialidades para o desenvolvimento cognitivo dos alunos.

\section{Referências}

Alencar, E., \& Fleith, D. (2003). Contribuições teóricas recentes ao estudo da criatividade. Psicologia: teoria e pesquisa", 19 (1), p. 1-8.

Borba, M. C. A. (2004) Pesquisa Qualitativa em Educação Matemática. In Reunião Anual da Anped.

Bachelard, G. (2006). A epistemologia. Lisboa: Edições 70.

Brasil. (1998). Parâmetros Curriculares Nacionais. Secretaria de Educação Fundamental. Brasília: MEC / SEF.

Brasil. (2015). Base nacional comum curricular. Brasília: MEC.

Ceará. (2019). Documento Curricular Referencial do Ceará (DCRC). Fortaleza: SEDUC.

Cerqueira, C. A., \& Sawyer, D. R. O. T. (2007). Tipologia dos estabelecimentos escolares brasileiros. Revista Brasileira de Estudos de População,24 (1), p. 53-67. Disponível em: http://www.scielo.br/scielo.php?script=sci_ arttext\&pid=S0102-30982007000100005\&lng $=$ pt\&nrm $=$ iso

Damasceno Júnior, J. A. (2020). O papel do erro no processo de ensino e aprendizagem de Ciências e Matemática: contributos da Neurociência. Revista Prática Docente, 5 (2), p. 1171-1190. Disponível em: http://periodicos.cfs.ifmt. edu.br/periodicos/index.php/rpd/article/view/759.

Damasceno Júnior, J.A., \&Romeu, M. C. (2018). O Planetário como recurso metodológico para facilitar o ensino de Física por meio da ruptura entre o conhecimento científico e o conhecimento comum. Revista Prática Docente, 3 (1), p. 231-248. Disponível em: http://periodicos.cfs.ifmt.edu.br/periodicos/ index.php/rpd/article/view/206

Dornelles, A. B. T. B., Cruz, C. A., Medeiros, E. M. S., Araújo, J. V. A., Villacorta, K. D. V., \& Buriti, L. C. L. (2019). Robótica Educacional e Pensamento Computacional: uma Avaliação da Percepção dos Alunos sobre o Tema. In Anais do IV Congresso sobre Tecnologias na Educação. Disponível em: https:// sol.sbc.org.br/index.php/ctrle/article/view/8927

Duarte, M. R. T., Gomes, C. A.T., \& Gotelib, L. G. O. (2019). Infrastructure conditions of Brazilian schools: A needy school for the needy? Education policy analysis archives, 27 (1), p. 70.Disponível em: https://epaa.asu.edu/ojs/article/view/3536

Gavassa, R. C. F. B., Munhoz, G. B., Mello, L. F., \& Carolei, P. (2016). Cultura maker, aprendizagem investigativa por desafios e resolucão de problemas na SME-SP (Brasil). In FabLearn Brasil. Disponível em: http://104.152.168.36/ fablearn/ wp-content/uploads/2016/09/FLBrazil 2016 paper 127.pdf

Lima, S. C., \& Takahashi, E. K. (2013). Construção de conceitos de eletricidade nos anos iniciais do Ensino Fundamental com uso de experimentação virtual. Revista 
Brasileira de Ensino de Física, 35 (3), p. 1-11. Disponível em: https://www.scielo. br/scielo.php?pid=S1806-11172013000300020\&script=sci arttext\&tlng=pt

Lopes, L. O., Oliveira, P.R. P., Santos, K. F., Pomari, E., \& Thuler, D. (2019). O Maker na Escola: uma Reflexão sobre Tecnologia, Criatividade e Responsabilidade Social. In Anais do IV Congresso sobre Tecnologias na Educação. Disponível em: https://sol.sbc.org.br/index.php/ctrle/article/view/8908

Magalhães, C., \& Morais, C. (2017). Espaços Maker como locais não-formais de Educação em Ciências. In III Encontro em Ensino e Divulgação das Ciências.

Medeiros, J., Bueira, C. L., Peres, A., \& Borges, K. S. (2016). Movimento maker e educação: análise sobre as possibilidades de uso dos Fab Labs para o ensino de Ciências na educação Básica. In Fablearn Brasil. Disponível em: https:// fablearn.org/wp-content/uploads/2016/09/FLBrazil 2016 paper 33.pdf

Meira, S. L. B., \& Ribeiro, J. L. P. (2016). A Cultura Maker no ensino de Física: construção e funcionamento de máquinas térmica. InFablearn Brazil. Disponível em: https://fablearn.org/wp-content/uploads/2016/09/ FLBrazil 2016 paper 55.pdf

Moreira, M. A. (2017). Grandes desafios para o ensino da Física na educação contemporânea. Revista do Professor de Física, 1(1), 1-13. Disponível em: https://periodicos.unb.br/index.php/rpf/article/view/7074

Rodrigues, D. P.; Mota, A. T., \& Souza, P. V. S. (2019). Circuitos Elétricos com Materiais de Baixo Custo: uma proposta pautada na aprendizagem significativa de Ausubel. Revista do Professor de Física, 3 (1). Disponível em: https://periodicos.unb.br/index.php/rpf/article/view/13429

Santana, A., Raabe, A., Santana, L., Metzger, J., Gomes, E., \& Vieira, M. (2016) Atividades Maker no Processo de Criação de Projetos por Estudantes do Ensino Básico para uma Feira de Ciências. Anais do Workshop de Informática na Escola. Disponível em: https://br-ie.org/pub/index.php/wie/article/view/6615

Santos, F. L., Nascimento, F. M. S., \&Bezerra, R. (2010). Reduc: A Robótica Educacional como abordagem de baixo custo para o ensino de computação em cursos técnicos e tecnológicos. In Anais do Workshop de Informática na Escola. Disponível em: https://www.br-ie.org/pub/index.php/wie/article/view/2053

Sátyro, N., \& Soares, S. A. (2007). Infraestrutura das escolas brasileiras de ensino fundamental: um estudo com base nos censos escolares de 1997 a 2005. Texto para Discussão, Brasília: Ipea. Disponível em: http://repositorio.ipea.gov.br/ handle/11058/1752

Silva, J. B., \&Sales, G. L. (2018). Atividade experimental de baixo custo: o contributo do ludião e suas implicações para o ensino de Física. Revista do Professor de Física, 2 (2). Disponível em: https://periodicos.unb.br/index.php/rpf/article/ view/12076

Silva, J. B., Sales, G.L., \& Castro, J. B. (2019). Gamification as an active learning strategy in the Physics education. Revista Brasileira de Ensino de Física, 41 (4). Disponível em: https://www.scielo.br/scielo.php?pid=S1806$11172019000400502 \&$ script $=$ sci arttext\&tlng $=$ pt

Silva, K. M. E., \& Batinga, V. T. S. (2019). O ensino de ciências e movimento maker: o caso da política de ensino da Rede Municipal do Recife-PE. In XII Encontro Nacional de Pesquisa em Educação em Ciências - XII ENPEC. Disponível em: http://abrapecnet.org.br/enpec/xii-enpec/anais/resumos/1/R1033-1.pdf

YIN, R. K. (2001). Estudo de caso: planejamento e métodos. Porto Alegre: Bookman. 